\title{
Systematic Review of Laparoscopic versus Robotic Hiatal Hernia Repair
}

\author{
Danilo Coco $^{1 *}$, Silvana Leanza ${ }^{2}$ \\ ${ }^{1}$ Department of General Surgery, Ospedali Riuniti Marche Nord, Pesaro, Italy; ${ }^{2}$ Department of General Surgery, Carlo Urbani \\ Hospital, Jesi, Ancona, Italy
}

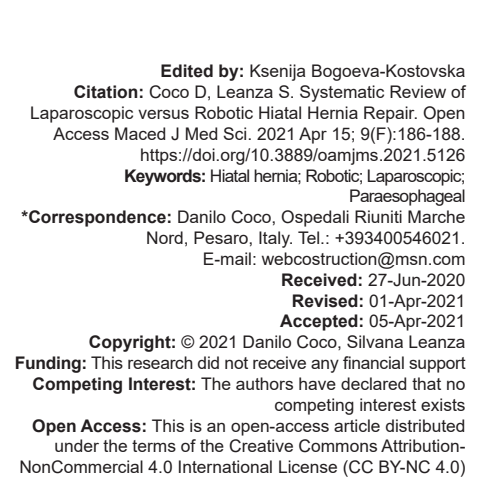

\section{Introduction}

Nowadays, elective surgical hiatal hernia $(\mathrm{HH})$ repair has not standardized intraoperative techniques remaining with a considerable recurrence rate between $10 \%$ and $26 \%$ [1], [2]. International guidelines recommended laparoscopic paraesophageal hernia repair (LPHHR) as gold-standard technique. LPEHR is associated with a reduced rate of perioperative morbidity and shorter hospital stay compared with outcomes of the open approach. In the last few decades, the use of robotic assisted paraesophageal hernia repair (RA-HHR) has increased [3], [4], [5]. RA-HHR allows surgeons to operate more precisely compared to conventional laparoscopy due to the three-dimensional view and the enhanced manipulation of instruments [6], [7], [8], especially in challenging operations such as super-obese patients or during redo operations, proved out to have certain benefits when performed robotically, both for patients as well as for surgeons [9], [10], [11], [12], [13].

\section{Methods and Materials}

\section{Study selection}

A systematic literature search from the GOOGLE SCHOLAR, EMBASE, MEDLINE, and
PUBMED databases for studies published in the past 10 years (2010-2020) was conducted. Several terms were used in the search, including Hiatal hernia, robotic, laparoscopic, and paraesophageal

\section{Inclusion and exclusion criteria}

Criteria for inclusion

1. Comparison of conventional LPHHR to RA-HHR

2. Studies featuring over 30 patients were taken into account

3. Mortality and morbidity rate, conversion rate, ICU stay, 1-month mortality, and postoperative complications, quality of life (QoL).

\section{Criteria for exclusion}

Non-comparative studies between LPHHR to RA-HHR, low-quality studies, reviews, case reports, and abstracts that could not be obtained from the research published were left out.

\section{Outcomes of interest}

The following information was utilized for comparing patients on LPHHR to those undergoing RA-HHR: Mortality and morbidity rate, conversion 
rate, ICU stay, 1-month mortality, and post-operative complications, QoL between the RA-HHR cohort and LPHHR cohort.

\section{Outcomes}

Many studies demonstrated that LPHHR is an efficacious and safe therapeutic option for management of hiatal hernia, prevention of recurrence, and relief of symptomatic GERD. In a study of a total of 221 patients underwent LPHHR, only 8 patients $(3.6 \%, 8 / 221)$ have had a documented anatomic hiatal hernia recurrence. About QoL the study demonstrated $86.6 \%$ of patients (149/172) were satisfied, and only $4.7 \%$ (8/172) were dissatisfied (23).

LPHHR leads to less post-operative pain than the open method. The tiny incisions of minimally-invasive surgery are unlikely to be compounded by wound infection and incisional hernias. There is reduction in post-operative respiratory complications [4]. Results from numerous studies are identical, with shorter stay in hospital and less morbidity arising from the minimally invasive method. The rates of recurrence are identical between LPHHR and RA-HHR [3], [12], [13]. Indeed, thanks to tiny incisions and decreased tissue trauma, patients that undergo robotic alongside other less invasive hernia repair surgeries return to normal duties more quickly, including particularly shorter stays in hospital. For instance, a study conducted by Carbonell et al. (2018) reported that robotic urgery patients that underwent hernia repair were discharged significantly sooner as opposed to those on open surgery [1], [14], [15].

A study by Chang et al. (2011) reviewed 12 scenarios of robotic and 12 scenarios for laparoscopic hernia surgical repairs, reported that robotic assisted surgery took longer compared to laparoscopic ones; this increased hospital expenses and presented further risks to the patient. The study concluded that robotic hernia repair was effective, safe, and feasible [2], [16], [17]. An observational study suggests technical feasibility for minimal-invasive robot-assisted redo surgery after open primary antireflux surgery. This study demonstrated a reduced number of conversions and shorter hospital stay with robotic surgery in REDO antireflux surgery 2.0 years after primary surgery based on single institute cohort of 75 patients who underwent either conventional laparoscopic or robot-assisted laparoscopic surgery for recurrent GERD or severe dysphagia between 2008 and 2013. The number of conversions was lower in the robot-assisted group compared to conventional laparoscopy (1/45 vs. 5/30, p = 0.035) despite a higher proportion of patients with previous surgery by laparotomy (9/45 vs. $1 / 30, p=0.038)$. Complications rate were comparable [18], [19], [20], [21]. Soliman et al. performed a retrospective analysis of 293 consecutive patients who underwent elective hiatal hernia repair using either a laparoscopic $(n=151)$ or a robotic $(n=142)$ technique. They concluded that the hospital length of stay was significantly shorter $(1.3 \pm 1.8$ vs.
$1.8 \pm 1.5$ days, $p=0.003$ ) and there were significantly lower rates of complications (6.3 vs. $19.2 \%, p=0.001$ ) after robotic compared to LPHHR. There was no difference in readmission rate and mortality [22].

\section{Limitations}

There are numerous limitations in the review. First, the review focused solely on English literature. Second, the selection and search of studies were conducted by two authors. Third, there was no balance in the studies concerning prosthetic meshes utilized, that is, non-absorbable, absorbable, and materials alongside configuration of repair. Fourth, the definition pertaining to the meaning of large hiatal hernia differed between studies. The main limitations are less number of manuscript that compare LPHHR and RA-HHR.

\section{Conclusion}

Repair of hiatal hernias is associated with an elevated recurrence rate, a fact that has long driven modifications to surgical technique between $10 \%$ and $26 \%$ [2]. This review represented the sequence of RA-HHR to date and the results appear to be comparable to those attained by the traditional laparoscopic approach. RA-HHR constitutes a safe procedure with a learning curve of around 36 cases. With more experience, the complications, hospital, and operation time reduce without undermining the principles of surgery. Future studies with large patient cohorts alongside prospective $\mathrm{RCTs}$ are required to prove the durable nature of the procedure as opposed to the existing laparoscopic approach. In addition, several concerns should be addressed to ascertain the feasibility, safety, and clinical outcomes of RA-HHR and LPHHR for elective surgical treatments of large hiatal hernias in the future. The two techniques produce comparable results in terms of complications and reoperation rate save for reduced time for RA-HHR. RA-HHR allows surgeons to operate more precisely compared to conventional laparoscopy due to the three-dimensional view and the enhanced manipulation of instruments [13], [14], [15], [16], [17], [18], [19], [20], especially in challenging operations. Nevertheless, there is need for further studies to prove the efficacy and long-term safety of certain forms of RA-HHR before its routine implementation [23].

\section{References}

1. Carbonell AM, Warren JA, Prabhu AS, Ballecer CD, Janczyk RJ, Herrera J, et al. Reducing length of stay using a robotic-assisted 
approach for retromuscular ventral hernia repair: A comparative analysis from the Americas hernia society quality collaborative. Ann Surg. 2018;267(2):210-7. https://doi.org/10.1097/ sla.0000000000002244

PMid:28350568

2. Rodriguez HA, Oelschlage BK. Secrets for successful laparoscopic antireflux surgery: Mesh hiatoplasty. Ann Laparosc Endosc Surg. 2017;2:50. https://doi.org/10.21037/ ales.2017.02.16

3. Cuschieri A, Shimi S, Nathanson LK. Laparoscopic reduction, crural repair, and fundoplication of large hiatal hernia. Am J Surg. 1992;163(4):425-30. https://doi. org/10.1016/0002-9610(92)90046-t

PMid:1532701

4. Chrysos E, Tsiaoussis J, Athanasakis E, Zoras O, Vassilakis JS XynosE. LaparoscopicvsopenapproachforNissenfundoplication. A comparative study. Surg Endosc. 2002;16(12):1679-84. https:// doi.org/10.1007/s00464-001-9101-y

PMid:11984689

5. Frantzides CT, Madan AK, Carlson MA, Zeni TM, Zografakis JG, Moore RM, et al. Laparoscopic revision of failed fundoplication and hiatal herniorraphy. J Laparoendosc Adv Surg Tech A. 2009;19(2):135-9. https://doi.org/10.1089/lap.2008.0245 PMid:19216692

6. Geha AS, Massad MG, Snow NJ, Baue AE. A32-year experience in 100 patients with giant paraesophageal hernia: The case for abdominal approach and selective antireflux repair. Surgery. 2000;128(4):623-30. https://doi.org/10.1067/msy.2000.108425 PMid:11015096

7. Granderath FA, Granderath UM, Pointner R. Laparoscopic revisional fundoplication with circular hiatal mesh prosthesis: The long-term results. World J Surg. 2008;32(6):999-1007. https://doi.org/10.1007/s00268-008-9558-0

PMid:18373118

8. Haider M, Iqbal A, Salinas V, Karu A, Mittal SK, Filipi CJ. Surgical repair of recurrent hiatal hernia. Hernia. 2006;10(1):139. https://doi.org/10.1007/s10029-005-0034-6 PMid: 16440130

9. Hunter JG, Smith CD, Branum GD, Waring JP, Trus TL, Cornwell $\mathrm{M}$, et al. Laparoscopic fundoplication failures: Patterns of failure and response to fundoplication revision. Ann Surg. 1999;230(4):595-604; discussion 604-596. https://doi. org/10.1097/00000658-199910000-00015 PMid: 10522729

10. Mark LA, Okrainec A, Ferri LE, Feldman LS, Mayrand S, Fried GM. Comparison of patient-centered outcomes after laparoscopic Nissen fundoplication for gastroesophageal reflux disease or paraesophageal hernia. Surg Endosc. 2008;22(2):343-7. https://doi.org/10.1007/s00464-007-9628-7 PMid: 18027047

11. Morris-Stiff G, Hassn A. Laparoscopic paraoesophageal hernia repair: Fundoplication is not usually indicated. Hernia. 2008;12(3):299-302. https://doi.org/10.1007/ s10029-008-0332-x

PMid: 18214636

12. Pitcher DE, Curet MJ, Martin DT, Vogt DM, Mason J, Zucker KA. Successful laparoscopic repair of paraesophageal hernia. Arch Surg. 1995;130(6):590-6. https://doi.org/10.1001/ archsurg.1995.01430060028006

PMid:7763166

13. Zehetner J, Demeester SR, Ayazi S, Kilday P, Augustin F, Hagen JA, et al. Laparoscopic versus open repair of paraesophageal hernia: The second decade. J Am Coll Surg. 2011;212(5):813-20. https://doi.org/10.1016/j. jamcollsurg.2011.01.060

PMid:21435915

14. Kohn GP, Price RR, DeMeester SR, Zehetner J, Muensterer OJ, Awad Z, et al. Guidelines for the management of hiatal hernia. Surg Endosc. 2013;27(12):4409-28. https://doi.org/10.1007/ s00464-013-3173-3 PMid:24018762

15. Rathore MA, Andrabi SI, Bhatti MI, Najfi SM, McMurray A. Metaanalysis of recurrence after laparoscopic repair of paraesophageal hernia. JSLS. 2007;11(4):456-60.

PMid: 18237510

16. Ruurda JP, Draaisma WA, van Hillegersberg R, Rinkes $I H$, Gooszen HG, Janssen LW, et al. Robot-assisted endoscopic surgery: A four-year single-center experience. Dig Surg. 2005;22(5):313-20. https://doi.org/10.1159/000088628 PMid:16192731

17. Morelli L, Guadagni S, Mariniello MD, Pisano R, D'Isidoro C, Belluomini MA, et al. Robotic giant hiatal hernia repair: 3 year prospective evaluation and review of the literature. Int $\mathrm{J}$ Med Robot. 2015;11(1):1-7. https://doi.org/10.1002/rcs.1595 PMid:24869751

18. Gehrig T, Mehrabi A, Fischer L, Kenngott H, Hinz U, Gutt CN et al. Robotic-assisted paraesophageal hernia repair a casecontrol study. Langenbecks Arch Surg. 2013;398(5):691-6. https://doi.org/10.1007/s00423-012-0982-0

PMid:22846911

19. Draaisma WA, Gooszen HG, Consten EC, Broeders IA. Midterm results of robot-assisted laparoscopic repair of large hiatal hernia: A symptomatic and radiological prospective cohort study. Surg Technol Int. 2008;17:165-70. https://doi. org/10.1097/00129689-200608000-00070 PMid: 18802897

20. Seetharamaiah R, Romero RJ, Kosanovic R, Gallas $M$, Verdeja JC, Rabaza J, et al. Robotic repair of giant paraesophageal hernias. JSLS. 2013;17(4):570-7. https://doi. org/10.4293/108680813×13654754534594

PMid:24398199

21. Tolboom RC, Draaisma WA, Broeders IA. Evaluation of conventional laparoscopic versus robot-assisted laparoscopic redo hiatal hernia and antireflux surgery: A cohort study. J Robot Surg. 2016;10(1):33-9. https://doi.org/10.1007/s11701-016-0558-z PMid:26809755

22. Soliman BG, Nguyen DT, Chan EY, Chihara RK, Meisenbach LM, Graviss EA, et al. Robot-assisted hiatal hernia repair demonstrates favorable short-term outcomes compared to laparoscopic hiatal hernia repair. Surg Endosc. 2020;34(6):2495502. https://doi.org/10.1007/s00464-019-07055-8 PMid:31385076

23. Chang CG, Thackeray L. Laparoscopic hiatal hernia repair in 221 patients: Outcomes and experience. JSLS. 2016;20(1):e2015.00104. https://doi.org/10.4293/jsls.2015.00104 PMid:26884676 